\section{SOI: $1.1 /$ TAS $\quad$ DOI: $10.15863 /$ TAS International Scientific Journal Theoretical \& Applied Science}

p-ISSN: 2308-4944 (print) e-ISSN: 2409-0085 (online)

Year: $2015 \quad$ Issue: 03 Volume: 23

Published: $30.03 .2015 \quad \underline{\text { http://T-Science.org }}$

SECTION 24. Sociological research.
Salim Balouch

ma in Educational Management-Visiting Lecturer, Islamic Azad University, Nikshahr branch, sistan\&balouchestan, Iran salim.balouch@gmail.com

Mehrbibi Bolide

ma in Management Planning courses-Visiting Lecturer, Islamic Azad University, Nikshahr branch, sistan\&balouchestan, Iran

Ziba Balouchi

ma in Philosophy of Education-Visiting Lecturer, Islamic Azad University, Nikshahr branch, sistan\&balouchestan, Iran zbalouchi@yahoo.com

Habibeh Raisi

ma in history-Visiting Lecturer, Islamic Azad University, Nikshahr branch, sistan\&balouchestan, Iran shoeibraisi@yahoo.com

\title{
WHAT IS THE IMPACT OF ORGANIZATIONAL SPIRITUALITY ON PRODUCTIVITY OF HUMAN RESOURCES?
}

\begin{abstract}
The present study aimed to investigate the impact of organizational spirituality on productivity of teachers of high schools of Nikshahr town in academic year 2014-2015. The present study is applied and is descriptive-correlation based on nature of study and study purpose. The study population is including all teachers of high schools of Nikshahr as 164 people. 113 people are selected by random sampling as a ratio of study population. Milliman survey of Workplace spirituality is used to evaluate work place spirituality and its reliability is 0.90 and Hersey and Goldsmith standard questionnaire is used to evaluate human resources and its reliability is 0.86. The data are analyzed at inferential statistics, correlation coefficient and multi-variate regression tests. The findings of study show that there is a positive and significant association between organizational spirituality and productivity of teachers. There is a positive and significant association between organizational spirituality and productivity of human resources components, except adjustment. Among the human resources productivity components, feedback and perception components with organizational spirituality have multiple correlation. Thus, increasing feedback and perception can predict the increase of organizational spirituality among the teachers.

Key words: Organizational spirituality, Productivity, Feedback, Teachers.

Language: English

Citation: Balouch S, Bolide M, Balouchi Z, Raisi H (2015) WHAT IS THE IMPACT OF ORGANIZATIONAL SPIRITUALITY ON PRODUCTIVITY OF HUMAN RESOURCES? ISJ Theoretical \& Applied Science 03 (23): 115-121.

Soi: http://s-o-i.org/1.1/TAS*03(23)21 Doi: crossef http://dx.doi.org/10.15863/TAS.2015.03.23.21
\end{abstract}

\section{Introduction}

Educational organizations are raised as the basic organizations as responsible for formal education of people in society and the schools as basic principle of formal education organization attempt to fulfill education [1]. Human resources of organizations are one of the most important components and capital of each organization. The development of human knowledge and various innovation in various sectors and its application in organizations have led to complexity in organizations and not only the importance of human being is reduced in various fields of human knowledge, but also the sensitivity of human resources of organization is [2]. Thus, to have a dynamic organization and be coordinated with other organizations, we should take a special attention to human resources and their needs and one of them is considering spiritual needs of people in organization. Spirituality in organization is organizational facilities for experiencing spirituality of employees of their work and spiritual feeling of employee by his job [3].Spirituality at work place is a field like learning processes in organization and helps to perceive issues of leadership and management [4]. The people who feel they can bring spiritual values to workplace are happier and productive compared to those who can not and they stay more and help the organization [5].Thus, one of 
the effective variables on organizational spirituality is human resources productivity in organization. The most important productivity factor in organizations and total society is human resources and actualization of each society is based on the improvement of its human resources. Thus, organizations by the aid of behavioral experts and human resources focus their attention on developing the employees [6].Productivity at employees level depends upon the analysis, measurement and improvement of human resources productivity as direct or indirect labor force [7].Awareness of employees productivity one hand leads to improvement of their condition and on the other hand by increasing products and services volume can make great changes in their movement and this trend helps fulfilling macro organizational goals. If employees and organization members think that their efforts are evaluated exactly and if their wage is consistent with their task, we can say, organization is at best condition in terms of creating motivation [8].Some of the components of productivity of human resources are investigated in relation to spirituality of workplace as ability: One's ability to do the works in an organizational position. In other words, ability is work evaluation or the action done by a person. Recognition and perception: It is the process by which a person can interpret his feeling and can give meaning based on environment[9].Organizational support: It reflects general beliefs of employees about organization. These beliefs arising from work experiences reveal for the employees that how much the organization gives importance to their efforts and gives value for their contribution and how much cares for their health [10].Motivation: Motivation is the main factor of the behavior of all people and is a progressive force in motivating and encouraging people [11].Adjustment: Adjustment is the ability of combination, consistency, compromise, collaboration and dealing with self, environment and others [12].Feedback: Informal presentation of one's daily performance and periodical formal visits [9].Many researches have been conducted regarding spirituality at work place with human resources performance in organization. In the study [13] regarding the effective components on human resources productivity in a health organization and military health, it was found that mental-intellectual growth, organizational support, organizational culture, job clarity explain organizational productivity changes . In a study [14] regarding the evaluation of the importance of identified components of human resources productivity from the view of employees and faculty members of Medical Sciences University of Gilan, it was found that organizational culture, motivational factors, environmental conditions, employees empowerment and leadership method were the most important factors of improving human resources productivity in Medical Sciences University of Gilan. Organizational culture is of great importance compared to other factors. Thus, the present study attempts to evaluate the impact of spirituality at work place on employees productivity? Are productivity components predict organizational spirituality? The hypotheses as followings are raised:1- There is a significant relation between organizational spirituality and productivity of teachers. 2 - There is a significant relation between organizational spirituality and components of human resources productivity. 3-A combination of productivity components can predict organizational spirituality of teachers.

\section{Study method}

The present study is applied and is descriptivecorrelation based on nature of study and purpose of study. The study population is all teachers (men and women) in academic year 2014-2015 as 164. The sample size is 113 by Morgan Table and relative stratified sampling method is used. Milliman et al., (2003) survey of Workplace spirituality is used to evaluate work place spirituality and Hersey and Goldsmith (1980) standard questionnaire is used to evaluate human resources. To evaluate validity of work place spirituality survey and human resources productivity, the questionnaires are distributed among University Lecturers to state their opinion regarding the fit of questions and components with scales. Work place spirituality survey includes 14 questions evaluating work place spirituality in meaning at work, correlation with others and consistency with organization values and Five-item Likert scale is used. Employees productivity survey consists of 27 items and five-item Likert scale is used in it and it evaluates the componets of ability, perception and recognition, organizational support, motivation, feedback, validity and adjustment. The reliability of questionnaires is calculated by Cronbach's alpha for organizational spirituality as 0.90 and organizational productivity 0.86 . The data are analyzed by Pearson correlation coefficient and multi-variate regression by SPSS, version 21 software.

\section{Findings}

Of 113 collected questionnaires, the descriptive data are as: Of total respondents there are 60 men $(53.1 \%)$ and $53(49.6 \%)$ women. Of total respondents, there are $13(11.5 \%)$ associate, 80 people $(70.8 \%)$ BA and 20 people $(17.7 \%)$ MA. 
Table 1

The mean and standard deviation of organizational spirituality and human resources productivity.

\begin{tabular}{lccc}
\hline Variable & Mean & SD & N \\
\hline Organizational spirituality & 49.92 & 10.61 & $\mathbf{1 1 3}$ \\
Human resources productivity & 71.95 & 15.18 & $\mathbf{1 1 3}$ \\
\hline
\end{tabular}

As shown in Table 1, the mean and standard deviation of organizational spirituality are 49.92,
10.61, respectively and human resources productivity as 71.95 and 15.18 , respectively.

Table 2

The mean and standard deviation of human resources productivity components.

\begin{tabular}{lllll}
\hline No & $\begin{array}{l}\text { Human resources } \\
\text { productivity components }\end{array}$ & Mean & SD & N \\
\hline 1 & Ability & 10.37 & 4.62 & $\mathbf{1 1 3}$ \\
\hline 2 & Perception & 10.93 & 2.80 & $\mathbf{1 1 3}$ \\
\hline 3 & Organizational support & 8.34 & 3.19 & $\mathbf{1 1 3}$ \\
\hline 4 & Motivation & 8.96 & 2.86 & $\mathbf{1 1 3}$ \\
\hline 5 & Validity & 11.70 & 3.36 & $\mathbf{1 1 3}$ \\
\hline 6 & Consistency & 10.23 & 2.90 & $\mathbf{1 1 3}$ \\
\hline 7 & Feedback & 11.39 & 2.91 & $\mathbf{1 1 3}$ \\
\hline
\end{tabular}

As shown in Table 2, standard deviation and mean in ability component are $10.37,4.62$, respectively in perception and recognition as 10.93 and 2.80 , respectively in organizational support as $8.34,3.19$, in motivation 8.96 and 2.96 in validity as
11.70 and 3.36 and in consistency 10.23, 2.90 and finally in feedback as 11.39 and 2.91 .

Hypothesis: There is a significant relation between organizational spirituality and productivity of teachers.

Table 3

\section{Correlation between organizational spirituality and human resources productivity.}

\begin{tabular}{lll}
\hline Variable & $\mathbf{R}$ & Sig \\
\hline Organizational spirituality and human resources productivity & 0.615 & $\mathbf{0 . 0 0 0}$ \\
\hline
\end{tabular}

As shown in Table 3, correlation coefficient of organizational spirituality with human resources productivity is 0.615 and obtained significance level of organizational spirituality with human resources productivity is 0.00 as less than $0.05 \%$ and it is not significant and $\mathrm{HO}$ is rejected and study hypothesis is supported. It means that there is a significant relation between organizational spirituality and productivity of teachers. The correlation is positive, it means that by increasing organizational spirituality, productivity of teachers is increased.

Second hypothesis: There is a significant relation between organizational spirituality and productivity of human resources components.

Correlation between organizational spirituality and productivity of human resources components.

\begin{tabular}{|c|c|c|c|c|c|c|c|c|c|c|}
\hline No & Correlation & $\begin{array}{c}\text { Organiz } \\
\text { ational } \\
\text { spiritual } \\
\text { ity }\end{array}$ & Ability & $\begin{array}{c}\text { Percep } \\
\text { tion }\end{array}$ & $\begin{array}{c}\text { Organiz } \\
\text { ational } \\
\text { support }\end{array}$ & $\begin{array}{c}\text { Motivat } \\
\text { ion }\end{array}$ & $\begin{array}{c}\text { Valid } \\
\text { ity }\end{array}$ & $\begin{array}{c}\text { Adjustm } \\
\text { ent }\end{array}$ & $\begin{array}{l}\text { Feed } \\
\text { back }\end{array}$ & Sig \\
\hline 1 & $\begin{array}{l}\text { Organization } \\
\text { al } \\
\text { spirituality }\end{array}$ & 1 & & & & & & & & 0.000 \\
\hline 2 & capability & 0.316 & 1 & & & & & & & 0.000 \\
\hline 3 & $\begin{array}{l}\text { Perception } \\
\text { and }\end{array}$ & 0.567 & 0.293 & 1 & & & & & & 0.000 \\
\hline
\end{tabular}

ISPC The Best of European Innovations, 


\begin{tabular}{|c|c|c|c|c|c|c|c|c|c|c|}
\hline & recognition & & & & & & & & & \\
\hline 4 & $\begin{array}{l}\text { Organization } \\
\text { al support }\end{array}$ & 0.520 & 0.305 & 0.566 & 1 & & & & & 0.000 \\
\hline 5 & Motivation & 0.383 & 0.309 & 0.339 & 0.615 & 1 & & & & 0.000 \\
\hline 6 & Validity & 0.496 & 0.417 & 0.442 & 0.531 & 0.563 & 1 & & & 0.000 \\
\hline 7 & Adjustment & 0.051 & 0.036 & -0.025 & -0.017 & -0.054 & 0.225 & 1 & & 0.294 \\
\hline 8 & Feedback & 0.586 & 0.469 & 0.566 & 0.575 & 0.562 & 0.630 & 0.077 & 1 & 0.000 \\
\hline
\end{tabular}

As shown in Table 4, correlation coefficient of organizational spirituality with ability 0.316 shows positive relation and low correlation with perception component 0.567 show positive relation and correlation at average level with organizational support component 0.520 show positive and correlation at average level with motivation component 0.383 indicates positive relation and correlation at low level with validity component 0.496 shows positive relation and correlation at average level with adjustment component 0.051 indicates positive relation and correlation at low level and finally with feedback 0.586 indicates positive relation and correlation at average level can be shown. Also, significance level of organizational spirituality with all human resources productivity components (except adjustment as significant with value 0.294 ) is 0.00 as less than $0.05 \%$. Thus, it is not significant and $\mathrm{HO}$ is rejected and $\mathrm{H} 1$ is supported. It means that there is a significant relation between organizational spirituality and all components of human resources productivity (except adjustment) and the correlation is positive, it means that by increasing organizational spirituality, all productivity components of teachers are increased. Also, the results show that there is a positive and significant correlation between all human resources productivity components (except adjustment with perception and recognition, adjustment with organizational support and adjustment with motivation).

Third hypothesis: A combination of productivity components predicts organizational spirituality of teachers.

Table 5

A summary of findings of regression analysis by stepwise method to predict organizational spirituality.

\begin{tabular}{lllll}
\hline \multicolumn{1}{c}{$\begin{array}{c}\text { Statistical indices of } \\
\text { components }\end{array}$} & $\begin{array}{c}\text { Multiple } \\
\text { correlation } \\
\text { coefficient }\end{array}$ & $\begin{array}{c}\text { Square } \\
\text { correlation } \\
\text { coefficient }\end{array}$ & $\begin{array}{c}\text { Adjusted } \\
\text { correlation } \\
\text { coefficient }\end{array}$ & $\begin{array}{c}\text { Estimated } \\
\text { standard } \\
\text { error }\end{array}$ \\
\hline entered in stepwise analysis & 0.586 & 0.344 & 0.388 & $\mathbf{8 . 6 3}$ \\
\hline Feedback & 0.652 & 0.425 & 0.415 & $\mathbf{8 . 1 1}$ \\
\hline Perception and recognition & & & \\
\hline
\end{tabular}

As correlation coefficients of other productivity components are weak, they are excluded from regression model. As shown in this table, in stepwise regression analysis, feedback, perception componets have multiple correlation with organizational spirituality. Based on importance, the order of predictive variables in stepwise regression analysis in the first step, feedback component with organizational spirituality has correlation coefficient 0.586 . IN the second step, by adding perception and recognition, correlation coefficient reached $0.652 \%$. The correlation coefficient value added for perception component is $0.06 \%$. Totally, these two components can explain $0.425 \%$ of organizational spirituality and $0.344 \%$ is dedicated to feedback and $0.08 \%$ to perception and recognition.

\section{Variance analysis for regression significance.}

Table 6

\begin{tabular}{cccccc}
\hline Model & Sum of squares & DF & Mean of squares & F & Sig \\
\hline Regression & 5361.18 & 2 & 2680.59 & 40.67 & 0.000 \\
Residual & 7250.24 & 110 & 65.91 & & \\
N & 12611.43 & 112 & - & \\
\hline
\end{tabular}


Based on the results of Table 6 , obtained $\mathrm{F}$ (40.67) as significant at error level smaller than 0.01 shows that it has high explanation power in independent variables and can explain the changes of dependent variable. Regression model of study is good and we can explain the changes of dependent variable of organizational spirituality based on two components of feedback and perception.

Standard and non-standard regression coefficients to predict organizational spirituality.

Table 7

\begin{tabular}{|c|c|c|c|c|c|}
\hline Statistical indices & Non-si & dard coefficients & $\begin{array}{c}\text { Beta } \\
\text { standard } \\
\text { coefficients }\end{array}$ & $\mathbf{T}$ & Sig \\
\hline Components & Beta & Standard error & & & \\
\hline Constant & 19.39 & 3.47 & - & 5.58 & 0.000 \\
\hline Feedback & 1.42 & 0.319 & 0.391 & 4.46 & 0.000 \\
\hline $\begin{array}{l}\text { Perception and } \\
\text { recognition }\end{array}$ & 1.30 & 0.332 & 0.345 & 3.94 & 0.000 \\
\hline
\end{tabular}

As shown in Table 7 , in stepwise regression analysis, in the final step (second step), two components of feedback and recognition to predict organizational spirituality entered regression equation. As shown in Table 7, feedback with beta coefficient 1.42 and $\mathrm{P}<0.000$ and perception and recognition with beta coefficient 1.42 and $\mathrm{P}<0.000$ have positive and significant relation. These results show that the increase of feedback and recognition predicts the increase of organizational spirituality among the teachers.

\section{Discussion and Conclusion}

The results of the study showed that there was a positive and significant association between organizational spirituality and human resources productivity components (except adjustment). Among human resources productivity components, feedback, perception and recognition components had multiple correlation with organizational spirituality. Thus, the increase of feedback and recognition predicts the increase of organizational spirituality among the teachers. The results of study are in line with the study of $[15,16,17,18,19]$. In a study done by [15]found that there was a positive relation correlation between spirituality and productivity. [16]showed that when employees experience spirituality at work place, they show high efficiency and productivity in organization. The study of [18] regarding spirituality and organizational performance shows that spirituality in organization supports organizational performance. Also, in the study of [19] it was found that spirituality at work place increases organizational performance. [20] shows that spiritual employees have significant and purposeful works and experiences and the results showed that organizational spirituality was formed via relation with other people and this shows sensitivity of employees with spirituality to the other's needs. Also[21] showed that spirituality had positive outcomes of work. Also, they found that when aggression is occurred at work place, spiritual employees were vulnerable to negative outcomes of work compared to those with low spirituality. In justification of the positive relation between organizational spirituality and employees' productivity, according to [22] attitudes, perceptions, feelings of employees are affected by their values and when people enter organizations, their values are formed and the norms of their behavior are affected. Thus, they prefer the behaviors to other behaviors. Thus, values cause that objectivity and organizational reasoning are affected. If one's values are along the organization goals and a person has positive attitudes, he can show positive behaviors. Positive behaviors from organizational behaviors show the increase of productivity of people in the organization. According to [23] promoting spirituality at work place leads to intuition and creativity, honesty, trust, self-success, commitment and improvement of organizational performance. Among components of human resources productivity, feedback and recognition predict organizational spirituality.

The results show that there is a positive and significant relation between organizational spirituality and human resources productivity. The following items are proposed for high productivity of organization: The attitude of education managers and school managers to spirituality at work place can help the improvement of these behaviors. Thus, performance of schools is increased by this method. Thus, managers should consider spirituality item at work place and attempt to improve spirituality at work place. The managers can improve perception of employees of spirituality at work place based on 
making work enjoying. One of the components of organizational spirituality is unity. It is proposed that by creating intimate climate and based on collaboration between teachers, can reduce stress of teachers and social capital is created in school and unity of teachers is increased. Survey of employees about values of education and considering health and life conditions of teachers can lead to acceptance of goals and values of education values from the teachers. If this is done truly, it leads to individual productivity and creates organizational productivity. It is proposed that top managers consider spiritual needs of teachers and attempt to create dynamic and motivating environment. The limitations of study are as respondents due to fear of losing their job position don't respond the questions and respond the questions of survey as conservatively.

\section{References:}

1. Zaki, Mohammad Ali (2009) The sociological evaluation of human resources productivity in education. Journal of human resources management researches of Imam Hossein Univeristy, Year 1. No. 2, pp. 172-147.

2. Salehi Sedghiani, Jamshid; Mohammadi Moghadam, Jamshid, Habibzade. Ashab ( 2009) The evaluation of effective factors on productivity of human resources of employees of security command of Lorestan province. Scientific-Research journal of social security. Year 1. NO. 1, pp. 93-103.

3. Shankar Pawar, Badrinarayan (2009) Individual spirituality, workplace spirituality \& work attitudes: An empirical test of direct \& interaction effects,Indian Institute of Management (Kozhikode), Kerala, India . Vol.30, No.8, pp.759-777.

4. Bosch L (2009) The inevitable role of spirituality in the workplace. Business Intelligence Journal, 2(1), 139 - 157.

5. Stevison M, Dent E, White D (2009) Toward a greater understanding of spirit at work: a model of spirit at work and outcomes. The academy of management proceedings, volume 2009 annual meeting proceedings.

6. Azad Marzabadi, Esfandiar; Hooshmandja, Manije; Pourkhalil, Majid (2012) The relationship between Organizational Spirituality and the Variables of Psychological Empowerment, Creativity, Spiritual Intelligence, Job Stress and Job Satisfaction among University Employees, Iranian Journal of Behavioral Sciences, Volume 6, No. 2.

7. Khaki GH (2010) Productivity Management. Tehran: Kohsar Publication, 45[Book in Persian].

8. Saadat, Esfandiar (2004) Human resources management. Tehran. SAMT.

9. Robins, P.Stephen (2009) The basics of organizational behavior. Translated by Ali
Parsayian and Seyed Mohammad Arabi. Tehran. Cultural research office

10. Makanjee, Chandra Rekha, Yolanda F. Hartzer and ilse L.uys. (2006) "The Effect of Perceived Organizational Support on Organizational Commitment of Diagnostic Imaging Radiographers", Radiography, 12: 118-126.

11. Nasrallahpour M (2006) Study of effective factors on Human Resource Productivity. Tadbir, 16(157): 10[Article in Persian].

12. Fooladi, Ezatollah (2004) Consulting of the peers: Visions, concepts of mental health and skills. Third edition. Tehran. Tolu Danesh publications.

13. Bahadori, Mohammad karim, Teimourzade, Ehsan and Mastry Farahani, Hossein (2013) Effective factors on productivity of human resources in a health and military organization. Military medicine journal. Period 15. NO. 1, pp. 75-86.

14. Mehrabian, Fardin; Nasiripour, Askhan and Keshavarz Mohammadian, Sakine (2011) The evaluation of the importance of identified components of human resources productivity from the view of employees and faculty members of Medical Sciences University of scientific-research journal of Medical Sciences University of Zanjan. Period 19, No. 75. pp. 94106.

15. Jamshidi Ghahghari, Fateme and Hayati, Zahir (2013) Evaluation of the impact of spirituality on human resources productivity in libraries. Librarian and information research. 3(1) 50727.

16. Raei Dehaghi, Morteza, Goodarzi, Masoud. Karimi Arazi, Zahra (2012) the effect of spiritual values on employees' organizational commitment and its models. Procedia - Social and Behavioral Sciences 62, $159-166$.

17. Kolodinsky, Robert.W.,Giacalone, Robert.w.A., Jurkiewicz, Carole.l (2008) Workplace values and outcomes: exploring personal, 
organizational, and interactive Workplace spirituality. Journal of Business Ethics, Volume 81, pp 465-480.

18. Rego, Arme 'nio\&Cunha, Miguel. Pina. E (2008) Workplace spirituality and organizational commitment: an empirical study. Journal of Organizational Change Management Vol. 21 No. 1, pp. 53-75.

19. Jurkiewicz, Carole. L\& Giacalone, Robert. A (2004) A Values Framework for Measuring the Impact of Workplace Spirituality on Organizational Performance. Journal of Business Ethics, Volume 49, Issue 2, pp 129142.

20. Tepper BJ (2003) Organizational citizenship behavior and the spiritual employee. In R. A. Giacalone \& C. L. Jurkiewicz (Eds.), Handbook of workplace spirituality and organizational performance (pp. 181-190). Armonk, NY: M. E. Sharpe.

21. Sprung, Justin M., Sliter, Michael T., Jex, Steve M (2012) Spirituality as a moderator of the relationship between workplace aggression and employee outcomes. Personality and Individual Differences, Volume 53, Issue 7, pp. 930-934.

22. Qolipour, Arian (2007) Management of organizational behavior (individual behavior). Tehran. SAMT.

23. Milliman, John F., \&rew J. Czaplewski \& Jeffery Ferguson (2003) Workplace spirituality \& employee work attitudes: An exploratory empirical assessment,Journal of Organizational Change Management, Vol. 16, No. 4, pp.426.447. 